Research Paper

\title{
Risk of Cancer in Patients with Insomnia, Parasomnia, and Obstructive Sleep Apnea: A Nationwide Nested Case-Control Study
}

\author{
Hui-Feng Fang1; Nae-Fang Miao ${ }^{2}$; Chi-Dan Chen 3 ; Trevor Sithole ${ }^{4,5}$; Min-Huey Chung ${ }^{\natural 凶}$ \\ 1. Deputy Director, Department of Nursing, Taipei Medical University Hospital, Taipei, Taiwan \\ 2. Assistant Professor, School of Nursing, College of Nursing, Taipei Medical University, Taipei, Taiwan \\ 3. Assistant, Graduate Institute of Nursing, College of Nursing, Taipei Medical University, Taipei, Taiwan \\ 4. Nurse, Maternity Department, Emkhuzweni Health Center, Swaziland \\ 5. Nurse, Customer Care Officer, Emkhuzweni Health Center, Swaziland \\ 6. Associate Professor, School of Nursing, Graduate Institute of Nursing, College of Nursing, Taipei Medical University, Taipei, Taiwan
}

$\triangle$ Corresponding author: Min-Huey Chung, RN, PhD, Associate Professor, Graduate Institute of Nursing, Taipei Medical University, 250 Wu-Xing Street, Taipei, Taiwan, 110, R.O.C. TEL: 886-2-27361661-6317; FAX:886-2-23772842; E-mail:minhuey300@tmu.edu.tw

() 2015 Ivyspring International Publisher. Reproduction is permitted for personal, noncommercial use, provided that the article is in whole, unmodified, and properly cited. See http://ivyspring.com/terms for terms and conditions.

Received: 2015.04.23; Accepted: 2015.07.30; Published: 2015.09.15

\begin{abstract}
Purpose: Insomnia, parasomnia, and obstructive sleep apnea have been associated with a number of disease pathologies, but little is known about the relationship of these sleep disorders and cancer. The study explored the risk of sleep disorder (SD)-induced cancer using nationwide population data. Two million data from the National Health Insurance system of Taiwan was used to assess for the relationship.

Patients and Methods: Patients with cancer as our cases and patients without cancer as our control group in 2001-20011. The study patients were traced back to seek the exposure risk factor of sleep disorders, which was divided into three categories: insomnia, obstructive sleep apnea (OSA) and parasomnia. Patients were selected excluding patients who had cancer prior to presenting with the sleep disorder and the person-year is less than 2 years. Each case was randomly matched with two cases with the same age, gender, and index year.

Results: There were significantly increased risks of breast cancer in the patients with insomnia $(\mathrm{AHR}=1.73 ; 95 \% \mathrm{Cl}: 1.57-1.90)$, patients with parasomnia $(\mathrm{AHR}=2.76 ; 95 \% \mathrm{Cl}: 1.53-5.00)$, and patients with OSA (AHR=2.10; 95\% Cl: 1.16-3.80). Moreover, patients with parasomnia had significantly higher risk of developing oral cancer (AHR=2.71; 95\% Cl: 1.02-7.24) compared with patients without parasomnia. The risk of suffering from nasal cancer $(A H R=5.96,95 \% \mathrm{Cl}$ : 2.96-11.99) and prostate cancer (AHR=3.69, 95\% Cl: 1.98- 6.89) in patients with OSA was significantly higher than that of patients without OSA.

Conclusions: Our findings provided the evidence that people diagnosed with insomnia, parasomnia and OSA are at a higher risk of developing cancers to remind people to improve sleep quality.
\end{abstract}

Key words: insomnia, parasomnia, obstructive sleep apnea, cancer

\section{Introduction}

Sleep is a naturally recurring state and biological phenomenon that fulfills the essential physiological and psychological needs of people. However, over time, the prevalence of sleep disorders (SDs) has in- creased worldwide. According to a review of epidemiologic studies on SDs, at least $10 \%$ of the Western population suffers from SDs that are clinically worthy of attention and crucial to public health (1). The prev- 
alence of SDs was $23.5 \%$ in the Japanese population, and a similar result was reported for Asian populations $(2,3)$. Sleep disorders are common in various societies worldwide, particularly in adult populations, and are related to distinct pathologies such as cardiovascular diseases (4), diabetes mellitus (5), total mortality (6), and cancer (7-9). SDs can either be sleep deprivation or disturbance (short duration of sleep or poor quality of sleep). Sleep disorders are categorized into different classes depending on its nature. The relationship between cancer risk and three categories of sleep disorders are discussed in this paper which are insomnia, parasomnia and obstructive Sleep Apnea (OSA).

According to the Diagnostic and Statistical Manual of Mental Disorders, Fourth Edition, Text version (DSM-IV-TR), insomnia is a persistent disorder that can hinder falling asleep, remaining asleep, or both, despite the opportunity for adequate sleep. Working night shifts has been associated with an increased risk of numerous cancers, including breast cancer (10-12) and colorectal adenomas (8), a precursor of colorectal cancer. Low sleep efficiency and a lot of sleep disruption are significantly independent risk factors in women with advanced breast cancer (13). The association studies between sleep duration and breast cancer risk suggested that breast cancer risk decreased with increasing sleep duration $(10,11)$. Similarly, 56\% lung cancer patients suffered sleep disturbance and that of $60 \%$ experienced psychological distress (14). Therefore, sleep disturbance is associated with the risk of developing cancer (15-17) and may serve as a health-threatening factor.

According to the American Sleep Academy, parasomnia is an SD characterized by undesirable physical events or experiences that occur when falling asleep, sleeping, or waking. Parasomnias includes disorders of arousal, rapid eye movement sleep behavior disorder, nocturnal seizures, rhythmic movement disorder, and sleep bruxism (18). This is a classification of SDs involving distinct sleep disruptions that are characterized by confusion, night terrors, and hallucinations. Previous studies indicated that parasomnias were associated with brain tumor $(19,20)$; some of the parasomnias were reported prior to cancer diagnosis (20) or after the cancer (19). In addition, Patients with RLS usually have uncomfortable sensations in their legs with compulsion to move, which make them to get up and walk around at night. Restless legs syndrome (RLS), a sensorimotor disorder, was reported as the presenting symptom of multiple myeloma (21). Rapid eye movement sleep behavior disorder (RBD) is frequent in patients with neurodegenerative diseases. RBD was associated with the risk of developing brainstem lymphoma (22).
Above evidence indicated that cancer frequently occurs in many individuals with parasomnias.

OSA is classified as disordered breathing during sleep that can cause sleep disturbance or deprivation and is associated with numerous pathologies, such as obesity, type 2 diabetes, the metabolic syndrome, and cardiovascular and neurophysiological diseases (23). Furthermore, OSA is associated with the risk of developing cancer (17). Studies have shown that sleep apnea can impair the health of individuals (24), such as by causing cardiovascular complications (25). Notably, sleep apnea has also been a sleep disorder of great clinical relevance because it is a syndrome with a relative incidence and prevalence of $33 \%$ of the population (24). The observation is supported by Campos-Rodriguez (2013) in the association between obstructive sleep apnea and cancer incidence in a large multicenter Spanish cohort. This previous study revealed a significant relationship of OSA and an increased risk of cancer but limited to men and patients with $\leqq 65$ years old (26).

Since sleep has a bidirectional relationship with most systems, changes in its pattern can generate negative consequences for the organism. Most researchers have focused on the topic of cancer-induced SDs $(27-29)$ or cross-sectional study $(30,31)$ when investigating the relationship between sleep problems and cancer. Few studies that show a relationship between nonapnea SDs and the risks of developing cancer have been published $(7,32)$. In the current study, we investigated specific cancer types in patients with 3 categories of SDs from a nationwide population to examine the association between SDs and the risk of developing cancer. In addition, this study explored the relationship between SDs and cancer in different ae group. Three SDs including insomnia, parasomnias and obstructive sleep apnea focuses on the three classifications which are sleep disorders with physiological hyperarousal, sleep disturbance, and disordered breathing. A large population-based study might help clarify concerns about the risk of SD-induced cancer.

\section{Method}

\section{Data Sources}

In this nested case-control study, 2 million samples were randomly selected from the National Health Insurance Research Database (NHIRD), which contains all of the claims data from the Taiwan National Health Insurance (NHI) program. The NHI program is a government-run system in Taiwan, and approximately $98 \%$ of the residents in Taiwan are enrolled in this system. All medical care providers are required to provide outpatient and inpatient services to NHI in- 
surant to claim fees from the NHI program (33). The medical claims information includes data on patient demographics, clinical details (disease and procedure codes according to the International Classification of Diseases, Ninth Revision, Clinical Modification (ICD-9-CM)), and health utilization (days in hospital, drug use, and charges). The National Health Research Institute (NHRI) maintains the database and releases deidentified secondary data to scientists and clinicians for research purposes. According to the Personal Information Protection Act, the identification of all beneficiaries is encrypted before release for research purposes. The Institutional Review Board of Taipei Medical University in Northern Taiwan approved this study (TMU-JIRB-201210001).

\section{Selection of Cases and Controls}

A cancer case was assembled by searching the outpatient and inpatient claims databases between January 1, 2001 and December 31, 2011 with any cancer diagnostic codes (ICD-9-CM codes 140 to 208) diagnosed by clinical physicians, which were randomly retrieved from the NHIRD. The cancer registry data were also confirmed from the Ministry of Health and Welfare. Moreover, patients aged $<18$ years and who had a history of antecedent cancer before 2001 were excluded, and the cancer cases comprised 68,422 patients. Two controls were frequency matched to each case according to age, sex, and year of cancer diagno- sis, and the control group contained 136,844 patients aged $>18$ to limit the study to an adult population. Figure 1 presents a flow chart for the selection of study participants.

\section{Exposure Ascertainment}

The exposure of interest included diagnosis of SDs diagnosed by clinical physicians at outpatient visits or during hospitalization with at least 2 service claims. The exclusion criteria for the SD group were (a) a previous diagnosis of SD before 1999, (b) a diagnosis of cancer at any time before the SD, and (c) cases with a latent period less than 2 years, because a latent period of at least 2 years exists between exposure and the development of clinically significant cancer (34). Based on the definition of exclusion, 4,843 measurements of SDs and 30,972 measurements of non-SDs from the cancer cases were obtained. The control group without cancer contained 10,226 measurements of SDs and 64,226 measurements of non-SDs. In this nested case-control study, we divided SD into 3 categories, namely insomnia (ICD-9-CM codes 307.40, 307.42, 307.44, 307.49, and 780.52), parasomnias (ICD-9-CM codes 307.46-307.49), and OSA (ICD-9-CM codes 327.23, 780.51, 780.53, and 780.57), for identifying the types of cancer in patients with these 3 types of SD. Insomniac patients who had comorbidity with parasomnia or OSA were categorized into parasomnia or OSA groups.

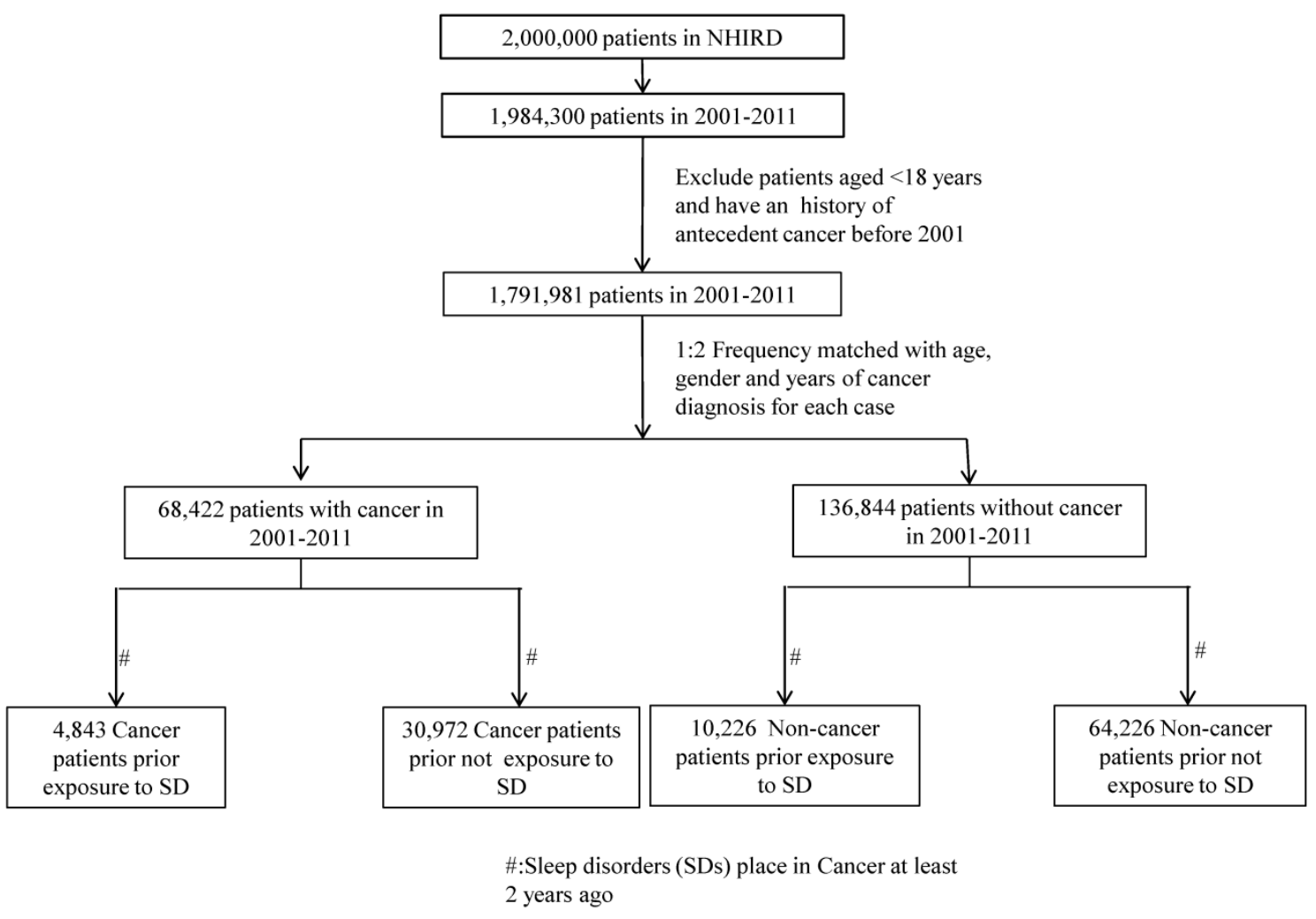

Figure 1. The flow of selection of Cases and Controls. 


\section{Statistical Analysis and Variables of Interests}

The SAS statistical package (SAS systems for Windows, Version 9.2; Cary, NC, USA) was used for performing the analysis, and the $\chi^{2}$ test was used for analyzing the difference in the demographic information between the study and comparison groups. We separated age into 3 groups: $<45,45$ to 64 , and $\geq$ 65 years. In addition, average monthly income level was divided into 3 groups: < US\$640 (NTD 20,000), US $\$ 640$ to 1,280 (NTD 20,000-39,999), and $\geq$ US $\$ 1,281$ (NTD 40,000). The Charlson Comorbidity Index (CCI) was divided into 2 groups: $<3$ (low comorbidity) and $\geq 3$ (high comorbidity) (35). The CCI is a scoring system which assigns between 1 and 6 points to a range of diseases (36). Four groups were established according to the geographical distributions of the participants: Northern, Central, Southern, and Eastern Taiwan. The urbanization level of the participants' residences was defined as urban, suburban, and rural. These related factors such as age, gender, income, region, and urbanization were related to sleep disorders $(7,37)$. The incidence density rate was defined as the number of incident cases divided by the sum of the person-time of the at risk population. The univariate Cox proportional hazard regression model was used for computing crude hazard ratios (CHRs) for developing cancer after diagnosis of insomnia, parasomnia, or OSA. The adjusted hazard ratio (AHR) represented the adjusted variables that differed significantly between the study and comparison groups by controlling age, gender, income, region, urbaniza- tion, and CCI. A $P$ value of $<.05$ was statistically significant.

\section{Results}

Table 1 shows the demographic characteristics of patients with cancer and without cancer from 2001 to 2011. After matching for age, gender, and year of cancer diagnosis, significant differences were found between patients with cancer and patients without cancer in terms of region, urbanization, and CCI (Table 1). Among the 68,422 patients with cancer included in this study, more percentage of the patients with cancer were observed to reside in Southern Taiwan $(29.65 \%)$ and in urbanized area (54.22\%); however, they yielded a higher CCI score $(51.25 \%)$ compared with the patients without cancer.

Table 2 presents the incidence density rate of cancers in the SD and Non-SD groups among the NHI enrollees. The significantly higher risk of cancer for the participants who aged $\geq 65$ years $(\mathrm{AHR}=1.22$; 95\% confidence interval [CI]: 1.17-1.27) compared with those in aged $<45$ years. The men had a significantly higher risk (AHR $=1.04 ; 95 \%$ CI: 1.02-1.06) compared with the women patients. The significantly higher risk of cancer for the participants who earned a lower monthly income level (US\$<640) $(\mathrm{AHR}=1.07$; 95\% CI=1.03-1.11) compared with those in higher income group. In addition, we determined significantly higher risk in patients who resided in Southern Taiwan (AHR $=1.04 ; 95 \%$ CI: $1.02-1.07$ ) than patients who resided in Northern Taiwan.

Table 1. Demographic characteristics of patients with cancer and without cancer

\begin{tabular}{|c|c|c|c|c|c|}
\hline \multirow{2}{*}{$\begin{array}{l}\text { Variable } \\
\text { Age (y) }\end{array}$} & \multicolumn{2}{|c|}{$\begin{array}{l}\text { Patients with cancer } \\
(N=68,422)\end{array}$} & \multicolumn{2}{|c|}{$\begin{array}{l}\text { Patients without cancer } \\
(N=136,844)\end{array}$} & \multirow{2}{*}{$\begin{array}{l}P \text { value } \\
.761\end{array}$} \\
\hline & $\mathrm{n}$ & $\%$ & $\mathrm{n}$ & $\%$ & \\
\hline$<45$ & 5,716 & 8.35 & 11,449 & 8.37 & \\
\hline $45-65$ & 26,889 & 39.30 & 53,993 & 39.45 & \\
\hline$\geq 65$ & 35,817 & 52.35 & 71,402 & 52.18 & \\
\hline \multicolumn{6}{|l|}{ Sex } \\
\hline Female & 31,206 & 45.61 & 62,412 & 45.61 & 1.000 \\
\hline Male & 37,216 & 54.39 & 74,432 & 54.39 & \\
\hline Income (US\$) & & & & & .555 \\
\hline$\geq 1,281(\geq \mathrm{NT} \$ 40,000)$ & 5,498 & 8.04 & 10,885 & 7.95 & \\
\hline $640-1,280(\mathrm{NT} \$ 20,000-39,999)$ & 9,410 & 13.75 & 18,645 & 13.63 & \\
\hline$<640(<\mathrm{NT} \$ 20,000)$ & 53,514 & 78.21 & 107,314 & 78.42 & \\
\hline Region & & & & & $<.001$ \\
\hline Northern & 30,197 & 44.13 & 60,580 & 44.27 & \\
\hline Central & 16,283 & 23.80 & 32,903 & 24.04 & \\
\hline Southern & 20,283 & 29.65 & 39,506 & 28.87 & \\
\hline Eastern & 1,659 & 2.42 & 3,855 & 2.82 & \\
\hline Urbanization & & & & & .011 \\
\hline Urban & 37,097 & 54.22 & 73,460 & 53.68 & \\
\hline Suburban & 24,146 & 35.29 & 48,502 & 35.44 & \\
\hline Rural & 7,179 & 10.49 & 14,882 & 10.88 & \\
\hline CCI & & & & & $<.001$ \\
\hline$<3$ & 33,357 & 48.75 & 71,196 & 52.03 & \\
\hline$\geq 3$ & 35,065 & 51.25 & 65,648 & 47.97 & \\
\hline
\end{tabular}

$\mathrm{CCI}$ : Charlson Comorbidity Index 
Table 2. Crude and adjusted hazard ratios for cancers in patients in the SD and Non-SD groups

\begin{tabular}{|c|c|c|c|c|c|}
\hline \multirow[t]{2}{*}{ Variable } & \multicolumn{5}{|l|}{ Cancer } \\
\hline & Cases & PY & Incidence $^{\dagger}$ & $\mathrm{CHR}(95 \% \mathrm{CI})$ & AHR $(95 \% \mathrm{CI})$ \\
\hline \multicolumn{6}{|l|}{ Age (y) } \\
\hline$<45$ & 3,286 & $64,310.5$ & 5.11 & 1.00 & 1.00 \\
\hline $45-65$ & 13,379 & $247,502.6$ & 5.41 & $1.12(1.08-1.16)^{* *}$ & $1.09(1.05-1.13)^{* * *}$ \\
\hline$\geq 65$ & 19,150 & $324,403.2$ & 5.90 & $1.32(1.27-1.37)^{\star *}$ & $1.22(1.17-1.27)^{\star *}$ \\
\hline \multicolumn{6}{|l|}{ Sex } \\
\hline Female & 15,707 & $277,874.9$ & 5.65 & 1.00 & 1.00 \\
\hline Male & 20,108 & $358,341.4$ & 5.61 & $1.03(1.00-1.05)^{*}$ & $1.04(1.02-1.06)^{\star * *}$ \\
\hline \multicolumn{6}{|l|}{ Income (US\$) } \\
\hline$\geq 1,281(\geq \operatorname{NT} \$ 40,000)$ & 3,026 & $56,271.3$ & 5.38 & 1.00 & 1.00 \\
\hline $\begin{array}{l}640-1280 \\
\text { (NT\$ 20,000-39,999) }\end{array}$ & 5,064 & $93,957.6$ & 5.39 & $1.00(0.96-1.05)$ & $1.01(0.97-1.06)$ \\
\hline$<640(<\mathrm{NT} \$ 20,000)$ & 27,725 & $485,987.4$ & 5.70 & $1.13(1.09-1.18)^{* *}$ & $1.07(1.03-1.11)^{* * *}$ \\
\hline \multicolumn{6}{|l|}{ Region } \\
\hline Northern & 15,762 & $283,233.0$ & 5.57 & 1.00 & 1.00 \\
\hline Central & 8.202 & $147,226.0$ & 5.57 & $1.02(1.00-1.05)$ & $0.99(0.97-1.02)$ \\
\hline Southern & 11,021 & $189,405.0$ & 5.82 & $1.06(1.03-1.08)^{* *}$ & $1.04(1.02-1.07)^{*}$ \\
\hline Eastern & 830 & $16,352.3$ & 5.08 & $0.93(0.87-1.00)^{*}$ & $0.89(0.83-0.95)^{* *}$ \\
\hline \multicolumn{6}{|l|}{ Urbanization } \\
\hline Urban & 19,430 & $344,311.9$ & 5.64 & 1.00 & 1.00 \\
\hline Suburban & 12,598 & $223,572.0$ & 5.63 & $1.01(0.99-1.03)$ & $0.99(0.97-1.01)$ \\
\hline Rural & 3,787 & $68,332.4$ & 5.54 & $1.00(0.96-1.03)$ & $0.97(0.94-1.01)$ \\
\hline \multicolumn{6}{|l|}{ CCI } \\
\hline$<3$ & 17,536 & $327,503.1$ & 5.35 & 1.00 & 1.00 \\
\hline$\geq 3$ & 18,279 & $308,713.2$ & 5.92 & $1.15(1.13-1.18)^{* *}$ & $1.01(0.99-1.04)$ \\
\hline \multicolumn{6}{|l|}{ Disease Group } \\
\hline Non-SD & 30,972 & $56,4048.8$ & 5.49 & 1.00 & 1.00 \\
\hline $\mathrm{SD}$ & 4,843 & $72,167.5$ & 6.71 & $1.76(1.70-1.81)^{\star *}$ & $1.71(1.66-1.77)^{* * *}$ \\
\hline
\end{tabular}

$\mathrm{SD}=$ sleep disorder; Non-SD = non-sleep disorder; CHR: crude hazard ratio using univariate cox proportional hazard regression model; AHR: adjusted hazard ratio using cox proportional hazard regression model by controlling for the variables of age, gender, income, region, area, and CCI; CCI: Charlson Comorbidity Index; $: P<.05$; $*$ : $P<$ 001; PY=person years; tper 1000 person-years.

We observed that the patients with SDs had a higher incidence density rate of cancers than did the patients without SDs (CHR $=1.76$; 95\% CI: 1.70-1.81). After the confounders of age, gender, income, region, urbanization, and CCI were adjusted, the AHR for cancers in the patients with SDs was significantly higher than that in the comparison group without SDs $(\mathrm{AHR}=1.71 ; 95 \% \mathrm{CI}: 1.66-1.77)$.

As shown in Table 3, the incidence, $\mathrm{CHR}$, and the AHR for cancer were both higher in the patients with SDs than in the patients without SDs. This study exhibited significantly increased risks of cancer in patients with SDs compared with the patients without SDs $(P<.001)$ in each age, sex, and CCI group. As shown in Table 4, we divided SDs into 3 categories, namely insomnia, parasomnia and OSA, for determining the specific relationship with cancers. After the confounders of age, sex, income, region, urbanization, and CCI were adjusted, significantly increased risks of breast cancer were observed in the patients with insomnia (AHR $=1.73$; 95\% CI: 1.57-1.90), parasomnia (AHR $=2.76 ; 95 \% \mathrm{CI}$ : 1.53-5.00), and OSA $(\mathrm{AHR}=2.10 ; 95 \% \mathrm{CI}: 1.16-3.80)$ compared with the comparison group. In addition, significantly higher risks of nasal cancer (AHR $=5.96$; 95\% CI: 2.96-11.99) and the prostate $(\mathrm{AHR}=3.69 ; 95 \% \mathrm{CI}$ : $1.98-6.89)$ were observed among patients with OSA as well as signif- icantly increased risks of oral cancer (AHR $=2.71 ; 95 \%$ CI: 1.02-7.24) in patients with parasomnia. Furthermore, patients with insomnia exhibited significantly increased risks of all types of cancer (tracheal, nasal, liver, cervical, oral, colon, lymphatic, thyroid, myeloma, prostate, bladder, and kidney) in this study.

\section{Discussions}

This nationwide population-based study of Asian people was to demonstrate the relationship between three specific SDs and the risk of developing cancer. The most valuable finding of this study is that the patients with SDs exhibited a higher risk of breast cancer compared with the patients without SDs. The same increased tendency of developing oral cancer in patients with parasomnias was observed. Moreover, the risk of developing nasal cancer in patients with OSA was extraordinarily high and that of developing prostate cancer was increased. Oral and nasal cancers have seldom been considered to be related with parasomnia and OSA in previous studies.

Patients with SDs had increased risk of cancer than patients without SDs (Table 2). This result confirmed the findings of internationally collaborative studies $(10,32,38,39)$, SDs increased cancer risk might be related to immunosuppression. In this study, patients with insomnia usually have a short 
duration of sleep while patients with parasomnias and OSA may disturb their sleep; especially the symptoms were present at night. The link between sleep disturbance and the suppression of the immune system might cause malignancies to establish and increase $(40,41)$, which have suggested that SDs patients with have an increased risk of breast cancer. However, the mechanisms need to be further explored in the future.

Table 3. The CHR and AHR for cancers in the SD and Non-SD groups according to the age, gender, and CCl

\begin{tabular}{|c|c|c|c|c|c|}
\hline \multirow[t]{2}{*}{ Variable } & \multicolumn{3}{|l|}{ Cancer } & \multicolumn{2}{|l|}{ Hazard ratio } \\
\hline & Cases & PY & Incidence & CHR (95\% CI) & AHR $(95 \%$ CI) \\
\hline All & 35,815 & $636,216.3$ & 5.63 & & \\
\hline Non-SD & 30,972 & $564,048.8$ & 5.49 & 1.00 & 1.00 \\
\hline SD & 4,843 & $72,167.5$ & 6.71 & $1.76(1.70-1.81)^{* *}$ & $1.71(1.66-1.77)^{* *}$ \\
\hline \multicolumn{6}{|l|}{ Age (y) } \\
\hline \multicolumn{6}{|l|}{$<45$} \\
\hline Non-SD & 3,068 & $61,505.6$ & 4.99 & 1.00 & 1.00 \\
\hline SD & 218 & $2,804.9$ & 7.77 & $2.56(2.23-2.94)^{\star *}$ & $2.32(2.02-2.68)^{\star *}$ \\
\hline \multicolumn{6}{|l|}{$45-65$} \\
\hline Non-SD & 11,835 & $224,047.3$ & 5.28 & 1.00 & 1.00 \\
\hline SD & 1,544 & $23,455.3$ & 6.58 & $1.89(1.79-1.99)^{* *}$ & $1.84(1.74-1.94)^{* *}$ \\
\hline \multicolumn{6}{|l|}{$\geq 65$} \\
\hline Non-SD & 16,069 & $278,495.9$ & 5.77 & 1.00 & 1.00 \\
\hline SD & 3,081 & $45,907.3$ & 6.71 & $1.57(1.51-1.63)^{\star *}$ & $1.61(1.55-1.67)^{* *}$ \\
\hline \multicolumn{6}{|l|}{ Gender } \\
\hline \multicolumn{6}{|l|}{ Female } \\
\hline Non-SD & 13,077 & $238,062.7$ & 5.49 & 1.00 & 1.00 \\
\hline SD & 2,630 & $39,812.2$ & 6.61 & $1.74(1.66-1.81)^{\star *}$ & $1.71(1.63-1.78)^{\star *}$ \\
\hline \multicolumn{6}{|l|}{ Male } \\
\hline Non-SD & 17,895 & $325,986.1$ & 5.49 & 1.00 & 1.00 \\
\hline SD & 2,213 & $32,355.3$ & 6.84 & $1.80(1.72-1.88)^{* *}$ & $1.73(1.65-1.81)^{* *}$ \\
\hline \multicolumn{6}{|l|}{ CCI } \\
\hline \multicolumn{6}{|l|}{$\mathrm{CCI}<3$} \\
\hline Non-SD & 16,120 & $308,122.8$ & 5.23 & 1.00 & 1.00 \\
\hline SD & 1,416 & $19,380.3$ & 7.31 & $2.12(2.01-2.24)^{\star *}$ & $2.06(1.95-2.18)^{\star *}$ \\
\hline \multicolumn{6}{|l|}{$\mathrm{CCI} \geq 3$} \\
\hline Non-SD & 14,852 & $255,926.0$ & 5.80 & 1.00 & 1.00 \\
\hline SD & 3,427 & $52,787.2$ & 6.49 & $1.56(1.51-2.62)^{\star *}$ & $1.58(1.52-1.65)^{\star *}$ \\
\hline
\end{tabular}

$\mathrm{SD}=$ sleep disorder; Non-SD = non-sleep disorder; $\mathrm{PY}=$ person years; ${ }^{\dagger}$ per 1000 person-years; CHR: crude hazard ratio using univariate cox proportional hazard regression model; AHR: adjusted hazard ratio using cox proportional hazard regression model by controlling for the variables of age, gender, income, region, area, and CCI; CCI: Charlson Comorbidity Index; CI: confident interval.

*: $\mathrm{P}<.05 ; * *: \mathrm{P}<.001$

Table 4. Incidence and AHR for cancer in the patients of 3 categories of SDs

\begin{tabular}{|c|c|c|c|c|c|c|c|c|c|}
\hline \multirow[t]{2}{*}{ Variable } & \multicolumn{3}{|c|}{ Patients with Insomnia } & \multicolumn{3}{|c|}{ Patients with Parasomnia } & \multicolumn{3}{|c|}{ Patients with OSA } \\
\hline & Case & Inc. ${ }^{\dagger}$ & $\operatorname{AHR}(95 \% \mathrm{CI})$ & Case & Inc. $^{\dagger}$ & $\mathrm{AHR}, 95 \% \mathrm{CI}$ & Case & Inc. ${ }^{\dagger}$ & $\operatorname{AHR}(95 \% \mathrm{CI})$ \\
\hline Tracheal Cancer & 551 & 0.74 & $1.61(1.47-1.77)^{* *}$ & 8 & 0.82 & $1.90(0.95-3.80)$ & 10 & 0.54 & $1.38(0.74-2.57)$ \\
\hline Nasal Cancer & 67 & 0.09 & $1.65(1.27-2.14)^{\star * *}$ & 3 & 0.31 & $5.00(1.61-15.52)$ & 8 & 0.43 & $5.96(2.96-11.99)^{* *}$ \\
\hline Liver Cancer & 706 & 0.95 & $1.35(1.24-1.46)^{* *}$ & 7 & 0.72 & $1.05(0.50-2.20)$ & 16 & 0.88 & $1.27(0.77-2.07)$ \\
\hline Breast Cancer & 517 & 0.69 & $1.73(1.57-1.90)^{\star *}$ & 11 & 1.13 & $2.76(1.53-5.00)^{\star * *}$ & 11 & 0.60 & $2.10(1.16-3.80)^{*}$ \\
\hline Cervical Cancer & 149 & 0.20 & $1.25(1.04-1.49)^{*}$ & - & - & - & - & - & - \\
\hline Oral Cancer & 211 & 0.28 & $2.07(1.78-2.40)^{\star *}$ & 4 & 0.41 & $2.71(1.02-7.24)^{*}$ & 6 & 0.33 & $1.63(0.73-3.64)$ \\
\hline Colon Cancer & 621 & 0.83 & $1.50(1.38-1.64)^{* *}$ & 9 & 0.93 & $1.75(0.91-3.37)$ & 14 & 0.76 & $1.55(0.92-2.63)$ \\
\hline Lymphatic Cancer & 85 & 0.11 & $2.18(1.71-2.77)^{\star *}$ & - & - & - & - & - & - \\
\hline Thyroid Cancer & 108 & 0.14 & $2.05(1.66-2.53)^{* *}$ & - & - & - & 3 & 0.16 & $2.66(0.85-8.28)$ \\
\hline Brain Cancer & 41 & 0.05 & $1.25(0.90-1.75)$ & - & - & - & - & - & - \\
\hline Myeloma Cancer & 66 & 0.09 & $1.52(1.16-1.98)^{*}$ & - & - & - & - & - & - \\
\hline Prostate Cancer & 222 & 0.30 & $2.13(1.83-2.46)^{* *}$ & 3 & 0.31 & $2.66(0.86-8.28)$ & 10 & 0.55 & $3.69(1.98-6.89)^{* *}$ \\
\hline Bladder Cancer & 166 & 0.22 & $1.85(1.56-2.19)^{* *}$ & - & - & - & 6 & 0.33 & $2.91(1.30-6.50)^{*}$ \\
\hline Kidney Cancer & 157 & 0.21 & $1.83(1.53-2.18)^{\star *}$ & - & - & - & 4 & 0.22 & $2.24(0.84-5.98)$ \\
\hline Other Cancer & 571 & 0.76 & $1.38(1.27-1.52)^{\star *}$ & 3 & 0.31 & $0.58(0.19-1.79)$ & 10 & 0.54 & $1.15(0.62-2.14)$ \\
\hline
\end{tabular}

tper 1000 person; AHR: adjusted hazard ratio using cox proportional hazard regression model by controlling for the variables of age, gender, income, region, area, and CCI; *: $P<.05 ;{ }^{* *}: P<.001$

ICD-9-CM codes:

Tracheal cancer: 162, nasal cancer: 147; liver cancer: 155; breast cancer: 174; cervical cancer: 180;

oral cancer: 140, 141, 144, 145, 146, 148; colon cancer: 153, 154; lymphatic cancer: 202; thyroid cancer: 193;

brain cancer: 191; myeloma cancer: 203, 205; prostate cancer: 185; bladder cancer: 188; kidney cancer: 189;

other cancer: 190, 192, 194, 195, 196, 197, 198, 199

_ : non applicable because of the sample size. 
This study recorded a significantly higher risk of prostate cancer in patients with OSA than did the patients without OSA, which was supported by other studies $(26,42)$. However, our results showed that patients with SDs exhibited a higher rate of nasal neoplasm than the comparison group, which was not mentioned in previous studies. Several factors might explain this result; the most crucial reason might be that nasal cancer is considered a virus-related malignancy (43), which might be consistent with our hypothesis of an SD-immunosuppression-viralinfection-cancer pathway. When the immune function is influenced, OSA might cause nasal malignancies to increase.

The result of this study showed that the risk of oral cancer was particularly high in patients with parasomnia than did the patients without parasomnia (Table 4), and this observation is supported by markedly few studies because this is a topic that has not been comprehensively studied. Moreover, epidemiologic studies have shown that SD patients frequently practice unhealthy lifestyles, including smoking and consuming alcohol $(44,45)$. Smoking and consuming alcohol are the main etiologic factors in oropharyngeal cancers(46) and, combined with insufficient sleep and a decreasing immune system, might explain the findings of our study. Sleep bruxism (SB), one kind of parasomnias, is that the magnitude of the parafunctional oromotor activity can affect the integrity of the structures of the masticatory(47). Therefore, the pathological effects of SB may alleviate oral cancer. However, the actual reason for this negative consequence remains to further exploring.

Table 2 indicates that risk increases as age increases, and thus, people aged 45 years and older were at a higher risk of developing cancer. The elder is supported by various studies, in which insomnia is referred to as a short duration of sleep $(8,9,48)$. A higher AHR in the male group compared with the female group was observed (AHR $=1.04 ; 95 \% \mathrm{CI}$ : 1.02-1.06). The sex difference in cancer susceptibility is one of the most consistent findings in cancer epidemiology and is supported by one previous study (49). In addition, we determined that SD patients with cancers were more likely to have a low income $(P<$. 001) and high percentage of CCI $(P<.001)$ because patients with a low income are likely to have inadequate access to medical care and treatment. This outcome is consistent with the research of socioeconomic status (50). Patients with a higher score or CCI score might have a higher range of disease to likely develop cancers compared with the general population, which is also supported by one previous study (51).

Our nested case-control study design and de- tailed information on various potential confounders constitute critical strengths of our study. Nevertheless, several potential limitations must be mentioned. First, we obtained no information on sleep duration, life styles (e.g. smoking, drinking), and family history of cancer, which can be crucial additional factors when assessing the severity of SDs. Second, despite controlling for various potential confounding factors in our research, we cannot exclude the possibility of unknown residual confounders; for instance, family history of cancer might account for these associations. Third, clinical physicians in different medical institutions might use different diagnostic criteria such like OSA. Some might use Apnea-Hypopnea Index $>5$ based on an overnight PSG recording as the diagnostic criteria but the others might use sleep apnea screening instruments to diagnose OSA. However, the validity of the diagnosis of SDs and cancer was enhanced by the requirement of at least 2 service claims for ambulatory care within 1 year and diagnosed by clinical physicians. Finally, the latent period of this nested case-control study between prior exposure to SDs and the development of cancer were at least 2 years. Future studies with longer latent durations are warranted to confirm this association and to clarify the association of chronic insomnia with cancer.

In conclusion, this nested case-control study revealed that people diagnosed with one of the 3 aforementioned SDs are at a higher risk of developing cancer than the patients without SDs, specifically breast cancer. The risk of developing nasal cancer and prostate cancer in patients with OSA was extraordinarily high, and the same increased tendency of developing oral cancer in patients with parasomnia was observed. Both men and women aged 45 years (or older) are at a higher risk of cancer when diagnosed with SDs. Further prospective studies, particularly those with more patient-level data are warranted for confirming our findings.

\section{Acknowledgment}

This study was supported by a grant (101TMU-TMUH-22) from Taipei Medical University Hospital, Taipei, Taiwan.

\section{Competing Interests}

The authors have declared that no competing interest exists.

\section{References}

1. Ram S, Seirawan H, Kumar SK, Clark GT. Prevalence and impact of sleep disorders and sleep habits in the United States. Sleep \& breathing = Schlaf \& Atmung. 2010; 14: 63-70.

2. Kaneita Y, Ohida T, Osaki Y, Tanihata T, Minowa M, Suzuki K, et al. Insomnia among Japanese adolescents: a nationwide representative survey. Sleep. 2006; 29: $1543-50$. 
3. Cho YW, Shin WC, Yun CH, Hong SB, Kim J, Earley CJ. Epidemiology of insomnia in korean adults: prevalence and associated factors. Journal of clinical neurology (Seoul, Korea). 2009; 5: 20-3.

4. Gilat H, Vinker S, Buda I, Soudry E, Shani M, Bachar G. Obstructive sleep apnea and cardiovascular comorbidities: a large epidemiologic study. Medicine. 2014; 93: e45.

5. Banerjee D, Leong WB, Arora T, Nolen M, Punamiya V, Grunstein R, et al. The potential association between obstructive sleep apnea and diabetic retinopathy in severe obesity-the role of hypoxemia. PloS one. 2013; 8: e79521.

6. Kripke DF, Langer RD, Kline LE. Hypnotics' association with mortality or cancer: a matched cohort study. BMJ Open. 2012; 2 .

7. Liang JA, Sun LM, Muo CH, Sung FC, Chang SN, Kao CH. Non-apnea sleep disorders will increase subsequent liver cancer risk--a nationwide population-based cohort study. Sleep medicine. 2012; 13: 869-74.

8. Thompson CL, Larkin EK, Patel S, Berger NA, Redline S, Li L. Short duration of sleep increases risk of colorectal adenoma. Cancer. 2011; 117: 841-7.

9. von Ruesten A, Weikert C, Fietze I, Boeing H. Association of sleep duration with chronic diseases in the European Prospective Investigation into Cancer and Nutrition (EPIC)-Potsdam study. PloS one. 2012; 7: e30972.

10. Verkasalo PK, Lillberg K, Stevens RG, Hublin C, Partinen M, Koskenvuo M, et al. Sleep duration and breast cancer: a prospective cohort study. Cancer research. 2005; 65: 9595-600.

11. Wu AH, Wang R, Koh WP, Stanczyk FZ, Lee HP, Yu MC. Sleep duration, melatonin and breast cancer among Chinese women in Singapore. Carcinogenesis. 2008; 29: 1244-8.

12. Pinheiro SP, Schernhammer ES, Tworoger SS, Michels KB. A prospective study on habitual duration of sleep and incidence of breast cancer in a large cohort of women. Cancer research. 2006; 66: 5521-5.

13. Palesh O, Aldridge-Gerry A, Zeitzer JM, Koopman C, Neri E, Giese-Davis J, et al. Actigraphy-measured sleep disruption as a predictor of survival among women with advanced breast cancer. Sleep. 2014; 37: 837-42.

14. Nishiura M, Tamura A, Nagai H, Matsushima E. Assessment of sleep disturbance in lung cancer patients: Relationship between sleep disturbance and pain, fatigue, quality of life, and psychological distress. Palliative \& supportive care. 2014: 1-7.

15. Sigurdardottir LG, Valdimarsdottir UA, Mucci LA, Fall K, Rider JR, Schernhammer E, et al. Sleep disruption among older men and risk of prostate cancer. Cancer epidemiology, biomarkers \& prevention : a publication of the American Association for Cancer Research, cosponsored by the American Society of Preventive Oncology. 2013; 22: 872-9.

16. Taylor DJ, Lichstein KL, Durrence $\mathrm{HH}$. Insomnia as a health risk factor. Behavioral sleep medicine. 2003; 1: 227-47.

17. Nozoe KT, Tufik S, Andersen ML. Is sleep related to cancer in murine models of obstructive sleep disorder? The European respiratory journal. 2012; 39: 1051.

18. Wills L, Garcia J. Parasomnias: epidemiology and management. CNS Drugs. 2002; 16: 803-10.

19. Rosen G, Brand SR. Sleep in children with cancer: case review of 70 children evaluated in a comprehensive pediatric sleep center. Supportive care in cancer : official journal of the Multinational Association of Supportive Care in Cancer. 2011; 19: 985-94.

20. Walker AJ, Pongsing Y, Nail L, Pedhiwala N, Leo M, Price J, et al. Sleep-wake patterns of school-age children and adolescents before diagnosis and during induction chemotherapy for acute lymphocytic leukemia. Journal of pediatric nursing. 2011; 26: e37-44

21. Arico D, Raggi A, Siragusa M, Zucconi M, Ferri R. Restless legs syndrome as the presenting symptom of multiple myeloma. Journal of clinical sleep medicine : JCSM : official publication of the American Academy of Sleep Medicine. 2013; 9: 383-5.

22. Jianhua C, Xiuqin L, Quancai C, Heyang S, Yan H. Rapid eye movement sleep behavior disorder in a patient with brainstem lymphoma. Internal medicine. 2013; 52: 617-21.

23. Botros N, Concato J, Mohsenin V, Selim B, Doctor K, Yaggi HK. Obstructive Sleep Apnea as a Risk Factor for Type 2 Diabetes. American Journal of Medicine, The. 2009; 122: 1122-7.

24. Tufik S, Santos-Silva R, Taddei JA, Bittencourt LR. Obstructive sleep apnea syndrome in the Sao Paulo Epidemiologic Sleep Study. Sleep medicine. 2010; 11: 441-6.

25. Cintra F, Tufik S, D'Almeida V, Calegare BF, de Paola A, Oliveira W, et al. Cysteine: a potential biomarker for obstructive sleep apnea. Chest. 2011; 139 : 246-52.

26. Campos-Rodriguez F, Martinez-Garcia MA, Martinez M, Duran-Cantolla J, Pena Mde L, Masdeu MJ, et al. Association between obstructive sleep apnea and cancer incidence in a large multicenter Spanish cohort. American journal of respiratory and critical care medicine. 2013; 187: 99-105.

27. Bouchard M, Reich M. [Insomnias in oncology: screening and management]. Bulletin du cancer. 2012; 99: 571-9.

28. Dickerson SS, Connors LM, Fayad A, Dean GE. Sleep-wake disturbances in cancer patients: narrative review of literature focusing on improving quality of life outcomes. Nature and science of sleep. 2014; 6: 85-100.

29. Matthews M, Hughes C, Rogers KM. Impact of counselling on quality of life and sleep in cancer patients. British journal of nursing. 2014; 23: S11-6.

30. Nandalike K, Strauss T, Agarwal C, Coupey SM, Sin S, Rajpathak S, et al. Screening for sleep-disordered breathing and excessive daytime sleepiness in adolescent girls with polycystic ovarian syndrome. The Journal of pediatrics. 2011; 159: 591-6.

31. Cheng KKF, Yeung RMW. Impact of mood disturbance, sleep disturbance, fatigue and pain among patients receiving cancer therapy. Eur J Cancer Care. 2013; 22: 70-8

32. Hu LY, Chen PM, Hu YW, Shen CC, Perng CL, Su TP, et al. The risk of cancer among patients with sleep disturbance: a nationwide retrospective study in Taiwan. Annals of epidemiology. 2013; 23: 757-61.

33. Huang CJ, Wang SY, Lee MH, Chiu HC. Prevalence and incidence of mental illness in diabetes: a national population-based cohort study. Diabetes research and clinical practice. 2011; 93: 106-14.

34. Su VY, Hu YW, Chou KT, Ou SM, Lee YC, Lin EY, et al. Amiodarone and the risk of cancer: a nationwide population-based study. Cancer. 2013; 119: 1699-705.

35. Charlson ME, Pompei P, Ales KL, MacKenzie CR. A new method of classifying prognostic comorbidity in longitudinal studies: development and validation. Journal of chronic diseases. 1987; 40: 373-83.

36. Thygesen SK, Christiansen CF, Christensen S, Lash TL, Sorensen HT. The predictive value of ICD-10 diagnostic coding used to assess Charlson comorbidity index conditions in the population-based Danish National Registry of Patients. BMC medical research methodology. 2011; 11: 83

37. Chung KH, Li CY, Kuo SY, Sithole T, Liu WW, Chung MH. Risk of psychiatric disorders in patients with chronic insomnia and sedative-hypnotic prescription: a nationwide population-based follow-up study. Journal of clinical sleep medicine : JCSM : official publication of the American Academy of Sleep Medicine. 2015; 11: 543-51.

38. Thompson CL, Li L. Association of sleep duration and breast cancer OncotypeDX recurrence score. Breast cancer research and treatment. 2012; 134: 1291-5.

39. Stevens RG. Light-at-night, circadian disruption and breast cancer: assessment of existing evidence. International journal of epidemiology. 2009; 38: 963-70.

40. Megdal SP, Kroenke CH, Laden F, Pukkala E, Schernhammer ES. Night work and breast cancer risk: a systematic review and meta-analysis. European journal of cancer (Oxford, England : 1990). 2005; 41: 2023-32.

41. Besedovsky L, Lange T, Born J. Sleep and immune function. Pflugers Archiv : European journal of physiology. 2012; 463: 121-37.

42. Kakizaki M, Kuriyama S, Sone T, Ohmori-Matsuda K, Hozawa A, Nakaya N, et al. Sleep duration and the risk of breast cancer: the Ohsaki Cohort Study. British journal of cancer. 2008; 99: 1502-5.

43. Wang L, Tian WD, Xu X, Nie B, Lu J, Liu X, et al. Epstein-Barr virus nuclear antigen 1 (EBNA1) protein induction of epithelial-mesenchymal transition in nasopharyngeal carcinoma cells. Cancer. 2014; 120: 363-72.

44. Crum RM, Storr CL, Chan YF, Ford DE. Sleep disturbance and risk for alcohol-related problems. The American journal of psychiatry. 2004; 161: 1197-203.

45. Phillips BA, Danner FJ. Cigarette smoking and sleep disturbance. Archives of internal medicine. 1995; 155: 734-7.

46. Chocolatewala NM, Chaturvedi P. Role of human papilloma virus in the oral carcinogenesis: an Indian perspective. Journal of cancer research and therapeutics. 2009; 5: 71-7.

47. de-la-Hoz JL. Sleep bruxism: review and update for the restorative dentist. The Alpha omegan. 2013; 106: 23-8.

48. Costa G, Haus E, Stevens R. Shift work and cancer - considerations on rationale, mechanisms, and epidemiology. Scandinavian journal of work, environment \& health. 2010; 36: 163-79.

49. Dorak MT, Karpuzoglu E. Gender differences in cancer susceptibility: an inadequately addressed issue. Frontiers in genetics. 2012; 3: 268

50. Chang CM, Su YC, Lai NS, Huang KY, Chien $\mathrm{SH}$, Chang $\mathrm{YH}$, et al. The combined effect of individual and neighborhood socioeconomic status on cancer survival rates. PloS one. 2012; 7: e44325.

51. Sarfati D, Gurney J, Stanley J, Lim BT, McSherry C. Development of a Pharmacy-based Comorbidity Index for Patients With Cancer. Medical care. 2014; 52: 586-93. 